\title{
American Society of Anesthesiologists physical status: how the obscurity in the system itself contributes to inaccuracies and variations in classification
}

\author{
Habib Md Reazaul Karim \\ Department of Anesthesiology and Critical Care, All India Institute of Medical Sciences, Raipur, India
}

The American Society of Anesthesiologists physical status (ASA-PS) classification is probably the most widely accepted and used risk classification system in perioperative practice. The ASA-PS also predicts patient outcomes. Therefore, the correct assignment of the ASA-PS class is very important in clinical practice. A recent article by De Cassai et al. [1] published in your journal discussed this issue and was read with great interest. The authors did an excellent job and showed that ASA-PS class assignment shows low inter-rater reliability. They also found that correct ASA-PS class assignment was lowest among the most experienced group and highest among the residents. This is probably because the residents had more theoretical knowledge of the ASA-PS classification, as per the 2014 updated definition [2]. It is generally agreed that practitioners must educate themselves with the updated literature and evidence; however, this has not been the case. An online survey on the updates in the recommendations and guidelines for pre-operative testing showed that nearly $52 \%$ of the responders did not have up-to-date knowledge

Corresponding author: Habib Md Reazaul Karim, M.D., D.N.B., I.D.C.C.M.

Department of Anesthesiology and Critical Care, All India Institute of Medical Sciences, Faculty Room A001, Block A, Great Eastern Road, Tatibandh, Raipur, Chhattisgarh 492099, India

Tel: +91-9612372585, Fax: +91-9612372585

Email: drhabibkarim@aiimsraipur.edu.in,drhabibkarim@gmail.com ORCID: https://orcid.org/0000-0002-6632-0491

Received: March 4, 2019.

Revised: March 13, 2019.

Accepted: March 18, 2019.

Korean J Anesthesiol 2019 October 72(5): 506-507

https://doi.org/10.4097/kja.19085 on the current recommendations and guidelines [3]. While the authors' findings and the explanations in the discussion are reasonable and well-accepted, more attention is required to a few facts beyond the knowledge/experience of the anesthesiologists.

The authors have developed case scenarios with regard to the ASA-PS classification of 2014. However, the obscurity of the ASA-PS classification itself may contribute to incorrect assignment and the variability observed. For example, in case scenario 5 from the authors' manuscript (survey), the patient had controlled hypertension, as well as chronic kidney disease stage I. In the ASA-PS classification, class II is assigned in cases of mild systemic diseases wherein there are no substantive functional limitations. This statement gives the reader tremendous scope to change class assignment. For example, irrespective of whether a patient has only one mild systemic disease or whether they have more, an ASA-PS class II status is assigned. In clinical practice, the involvement of multiple organ systems is serious and more detrimental to the health of a patient, even if the severity of individual organ dysfunction is mild. This obscurity and information likely lead to the assignment of a higher ASA-PS class to patients with two or more mild diseases. The authors' survey also showed the same findings: $44 \%-57 \%$ of respondents with different levels of experience designated case number 5 as ASAPS III, and some even designated it as class IV. Interestingly, residents performed poorer than others in this case, with only $33 \%$ providing the correct class assignment. This clearly indicates that only experience and knowledge are not enough for explaining the phenomena (i.e., variation in ASA-PS assignment). The need for education and being up-to-date with information cannot be denied, and the authors rightly mention and emphasize this point. However, we should also accept that there is a need to improve the ASA-PS classification further, in order to make it

(c) This is an open-access article distributed under the terms of the Creative Commons Attribution Non-Commercial License (http://creativecommons.org/ licenses/by-nc/4.0/), which permits unrestricted non-commercial use, distribution, and reproduction in any medium, provided the original work is properly cited. 
more accurate.

\section{Conflicts of Interest}

No potential conflict of interest relevant to this article was reported.

\section{Author Contributions}

Habib Md Reazaul Karim (Conceptualization; Resources; Writing-original draft; Writing-review \& editing)

\section{References}

1. De Cassai A, Boscolo A, Tonetti T, Ban I, Ori C. Assignment of ASA-physical status relates to anesthesiologists' experience: a survey-based national-study. Korean J Anesthesiol 2019; 72: 53-9.

2. ASA House of Delegates/Executive Committee. ASA Physical Status Classification System [Internet]. Schaumburg (IL): American Society of Anesthesiologists; 2014 Oct 15 [cited 2019 Mar 4]. Available from https://www.asahq.org/standards-and-guidelines/asa-physicalstatusclassification-system.

3. Karim HM. Practice and reasons for routine pre-operative investigations among anaesthesiologists and surgeons: an online survey. Indian J Anaesth 2017; 61: 933-5. 